\title{
Trafficking in Human Beings in Albania
}

\author{
Alma Nushi \\ Center for Albanian-American Studies \\ nushialma@yahoo.com
}

\section{Doi:10.5901/ajis.2015.v4n1p57}

\section{Abstract}

This research was conducted to show that trafficking is a major problem of our society after the 90s, when Albania came from the isolation of the communist regime and entered the transition stage. Human trafficking included not only exploitation for prostitution, but also illegal transportation of immigrants, the use of children and many other trafficking types. The trafficking took place individually in the beginning, then in a more organized form. The women and children were more affected by trafficking. Even the persons belonging to the poorest social strata were also affected by trafficking. Children belonging to the Roma and Egyptian communities were and are more exposed to the various exploitations and trafficking. Albania is seen as a destination of exploitation for prostitution of women coming from other countries in Eastern Europe. According to data, 8000 Albanian women are exploited for prostitution purposes in different European countries. The performed studies show that the number of trafficked persons increased during 1997-2001 and after 2002 the Albanian government took austerity measures to curb this bad phenomenon of our society. These kinds of trafficking seriously violate fundamental human rights protected by the European Convention of Human Rights. This study showed that trafficking as a phenomenon can be prevented if the Albanian government takes precautions against this trafficking as coercive measures and creates favorable conditions for the education of children and awareness of Albanian society to fight against these phenomena that violate the fundamental rights of Human beings such as the right of every man not to be enslaved by others, but to live his life with dignity and to put themselves on his life.

Keywords: Human Trafficking, Fundamental Human Rights, European Convention of Human Rights

The opening of Albania to other countries during the transition to democracy, alongside more positive sides brought the emergence of many problems for society.

The low economic level inherited from the past system, the lack of hope for a better life, the culture in terms of gender relations, the democratic culture sit, the inability to quickly build a better functioning state, the unemployment and other phenomena accompanied by wrong perceptions of realities outside our country, increased immigration trends in legal and illegal way, and thus developped the trafficking. As the world had such developments at the end of the last century, Albania had "to taste" this a decade ago.

The Albanian state and generally the Albanian society in active collaboration with international partners, has launched a tough and systematic fight against this phenomenon that appeared in the early 90s.It took place without "noise" in this period because the situation was more favorable.The extreme poverty pushed Albanians to get rid of principles and human feelings. The desire to earn as much money within a short time possible, invaded and obscured the minds of many people, who did not delay to raise their networks and to establish links with international networks of traffickers. Discussions and information about this phenomenon were almost absent. People and the state, felt that as little it was mentioned, the more will dodge its presence. Even when it became clear that trafficking had taken extraordinary proportions, it took many years to remove the emphasis from Albania's participation as a transit country, "due to its favorable geographical position". But now the people and the state are completely aware and accept that our country cannot only be considered as a transit country but also as a place of origin and destination (...)

In this context trafficking as a grave social injury, as one of the worst forms of violations of human rights and fundamental freedoms, led to deformation of basic social values and stimulated organized crime and corruption, creating a very negative image in the international arena for our country.

\section{Prostitution, as a Precursor to Trafficking}

Prostitution in itself implies a form of social behavior carried out contrary to the normal functioning of the relations between the sexes in society. The word "prostitution" has its origin from the Latin, and means lead astray, or pick up 
honor, humiliate, denigrate. While in the fullest sense would be sales, allocation of Honor, for purposes of profit. Prostitution is a particular problem that accompanied mankind to our days, but at the same time it remains one of the oldest wounds of world's civilizations. By treating the problem with a professional view, prostitution means a kind of work, in its classic form of sex for sale.

\subsection{What are the types of prostitution?}

This phenomenon has existed since the ancient times, and the studies that have been conducted in different periods of time show that it appeared in different types. As the oldest form displayed is the so-called ritual prostitution, which consists in carrying out sexual relations between men and women in certain cases and time, (on certain days of the week, month, or year). Such forms of prostitution were located in the Asian countries. Another form was, religious prostitution, which has appeared in intimate relationships performed by women, who served through temples. This category had various religious tasks and to provide sexual services to persons of different sex. Later another form known as substantial prostitution appeared as the commission of intimate relations between persons of different sexes, who were not connected by marriage. This type of relationship was considered as a kind of replacement due to the lack for a long time of the legitimate husband or wife. In modern societies appears another kind of prostitution, which is called professional prostitution, which constitutes the most widespread form of prostitution. This type of prostitution was already known in antiquity. In this period it was exercised in separate houses, which were called "public houses".

The phenomenon of prostitution has continued in the Middle Ages, but his problem was already seen otherwise. With the increasing authority of the church, the prostitution became strictly prohibited and its exercise was regarded as a serious crime punished by ecclesiastical laws. While nowadays this phenomenon is spread worldwide and is considered as a true social wound, which is more developped after the fall of communism. Prostitution generally occurs in the form of organized and unorganized prostitution. The organized form occurs when the state allows this phenomenon, but at the same time controls and oversees it and the places where prostitution is practiced are still referred called "public house". The unorganized form is when it is performed beyond state control and without its prior permission. In this case it is exercised sporadically and rather uncontrolled and hidden.

\subsection{What are the sociological views?}

There are different opinions in connection with the existence or not of prostitution in the world today and two of them have found more support in opinion.

First: The prevailing view that prostitution is an evil of society because it destroys monogamy in her bosom.It disrupts the balance of society in general and family in particular, and also is a source of sexually transmitted diseases.It is the carrier of the phenomenon of corruption and organized crime. Secondly, There is another perspective that prostitution is good for society. The society needs it because it realizes the excessive discharge of sexual tension and thus is able to respond better to the current life, which appears to become more intense in the whole of its phenomena.

General public considers this phenomenon as an illegal and aggressive action, and for this reason, it is seen as a social problem. Given some specific parameters, prostitution would be considered illegal only when it is exercised as a profession, when we are dealing with abandonment of mate connection and parental bonding. It takes illegal overtones even when it entails crime and corruption and when it is built on the enslavement and degradation of the individual. (Mecani, 2006)

\section{Types of Trafficking and Its Favoring Conditions}

The main feature of the development of the phenomenon of trafficking is its appearance under the guise of aid for prosperity to individuals who become victims. Its types and forms have evolved, becoming an important part of network crime and many material benefits. In this context, human trafficking itself contains three types of traffickers:

1. transport of refugees and illegal immigrants that includes all those people who migrate from one country to the other countries for protection and asylum for economic needs, employment, family union, health problems etc. Traffic immigrants includes the Albanian and foreign nationals, and its structure includes a large number of people traveling illegally into the country of destination.

2. Traffic in women, which includes all the girls and women who are recruited for sexual exploitation. Unlike the traffic of illegal immigrants, ending with the arrival at the destination, the traffic in women and exploitation begins here to 
continue there for years.

3. Trafficking of children, comprising children who are trafficked to be used for begging, sexual abuse, organ transplant, etc. Some of these children, especially girls, later are sold to traffickers of women for sexual exploitation.

What they have in common these types of traffickers: All three types are illegal trafficking, led by people with criminal activities come as a result of economic difficulties, methods of recruitment, (transport, doorways), exploitation for profit, the consequences for life (health, and social reintegration).

\subsection{Structural alignment.}

Besides trafficking types mentioned above, in Albania there are three types of networks and function of this phenomenon:

International network, which operates in several European countries. This network traffickers recruit women and girls from Eastern European countries and, through Albania, pass them to the countries of destination. This network is highly organized, has an active structure, including a large number of persons who perform acts for its implementation and operation. There are part of this network: Traffickers, companions, carriers, host, its drivers (vessels), the destination receiver, Protectorate, customers.

National Network operates in Albania and in some European countries. Traffickers come from different areas of the country and recruit women and girls from these areas, whom they use for exploitation of prostitution in countries of Europe and especially in Italy, France, Greece, Belgium, England, etc. Areas of smugglers of this network are: Tirana, Vlora, Durres, Berat, Korca, Fier and others. Even better, this network is highly organized because its members know the legislation of the countries where operating and circulate from one city to another within the state where they are located.

Individual traffickers dealers have to use a victim recruited by them or are men exploiting their women for prostitution. They recruit and perform in the areas of a single city of the state where they live. Mainly operating in Greece and Italy.(Pyscho-Social Centre"Vatra", 2003)

\subsection{Internal Trafficking situation}

As in the countries of the region, the phenomenon began to take place with frightening proportions after 90 s mainly after '93 -'94. Besides narcotics trafficking, trafficking in human beings became one of the most attractive. In the years 1993, 1994, 1995. trafficking processes were carried out by specific individuals, a phenomenon which, in the upcoming years, was being organized with a peak in the years 1997-2001. It was originally organized in clans independent groups based on kinship, tribal or social. The main forms of trafficking are women trafficking for sexual exploitation and trafficking of children for begging. The study of cases detected in the country and evidence of the returned girls show that criminal groups have used different methods to achieve this traffic, such as fraud, promises of marriage, employment or a better life, kidnapping, aiming prostutution in other countries or combination of the above methods. (Hysi, 2005)

For a long time this phenomenon was hit mainly on the basis of revenge and vigilantism of the affected families, due to the weak state structures, unprepared or corrupt. Only after 2000, the state had a serious reaction. After the year 2002-2003, Albania is not seen as a suitable place for the transit of victims, making it currently regarded as a country of origin mainly to the growing trend of destination for the purpose of prostitution. According to official estimates thought to be around 8,000 Albanian women exploited in different European countries. Recruitment of Albanian victims takes place mainly in rural areas, where most affected areas were the districts of Tirana, Durres, Vlora, Elbasan, Lushnja, Berat .This phenomenon has affected almost all districts. Albanian women are trafficked mainly in Italy, Greece, but also in Belgium and Great Britain.

During 2001, 113 cases of trafficking of women for prostitution were found and 192 women were rescued from trafficking, of which 57 foreign, mainly Moldovan, Romanian and Ukrainian. In 2002,the structures of the state police recorded 492 offenses that were for illegal trade with 778 authors. According to the criminal acts which constitute the object of the fight against illicit traffic, it turns out that for traffic of women for prostitution were identified 203 cases with 298 authors. (Leskaj et al,2004)

Likewise the child trafficking is a huge problem.It depends on the social strata and the children of Rom and Egyptian social groups are the most affected by this phenomenon. They are mainly trafficked to Greece and less in Italy.

They are trafficked for different purposes: exploitation for work, house work, sexual exploitation, but it is difficult to give exact data. According to ILO in the year 2000, 1.8 million children are exploited in the sex industry. Also they are trafficked for the purpose of illegal adoption, begging and organ transplantation. As a result of these illegal actions respective consequences are created, which are: emotional, physical, psychosocial, etc. 
The factors that put children at risk when they are associated with gender, racial or ethnic discrimination or insecurity caused by armed conflict and civil unrest, create the ideal environment to thrive trafficking networks. There are among them also other factors such as poverty, low school registration plates, children without caregivers, lack of birth registration plates, the demand for sexual services and cheap labor side. If these factors are not addressed, then direct measures to stop traffic would not be so successful. In this context,building a protective environment for children is required, which is essential to reduce their trafficking. First, Environment protection starts with the house; family represents the first line of defense. However, it is the duty of everyone, governments, teachers, religious leaders and police to help children have a safer life. Secondly, a protective environment requires that the government be interested to accept and engage in protecting children. It should be made available to child protection initiatives with sufficient resources, such as programs to combat child labor. Political leaders should also play a leading role to put the issue of child protection in the legislative agenda. (Handbook for Parlamentarians,2005)

\section{Overview Comparison between Albanian and International Legislation}

In this analysis, our legislation will be put in a comparative confrontation with the international standards, aiming to attract the conclusions for the level of fulfillment of these standards by our legislation through the identification of positive or negative aspects in order to made suggestions for further improvements. This analysis will start from the study of constitutional provisions which form the basis of our legal order and then we will proceed with the analysis of the provisions of the Criminal Code. Constitutional provisions that affect human trafficking are in the second part of the Constitution, which is divided into six chapters. Top I- provides "General Principles", Chapter II, "Personal Rights and Freedoms", Chapter III "Liberties and Political Rights, Chapter IV" Economic Liberties and Rights, Social, and Cultural Rights, Chapter V " Social Objectives ", Chapter VI" Ombudsman ". Also instrumental in (Section 3) is determined among other things: ".... human dignity, rights and freedoms are the basis of this state, which has the duty to respect and protect you."

The Constitution can and should be interpreted extensively in profile guaranteeing human rights. This interpretation requires that the state not to confine itself to the excellent self to not violate these rights, but to take measures to protect and create conditions for their realization. Our Constitution, as few others, explicitly considers the rights not only as subjective rights, but also as objective elements of the legal order, which oblige the political power of conformity to the content, protection and implementation. The Constitution does not leave to positive law determining the boundaries of the limitation of rights, but itself provides essential criteria of this restriction. These criteria can not violate another law. Such is the criterion of proportionality, which is the vehicle that allows the analysis of the content and not the form, and, therefore, constitutes the most prominent profile of jurisprudential policy. This criterion is provided in (Section 17) which stipulates as follows:

1. Limitations of rights and freedoms provided for in this Constitution may be established only by law and in the public interest or for the protection of the rights of others. The restriction must be proportionate to the situation that has dictated it.

2. These limitations may not infringe the essence of freedoms and rights and should in no case exceed the limitations set forth in the European Convention on Human Rights.

Our Constitution represents a number of features with regard to fundamental rights and freedoms, ranking it among the acts with European standards: First, we classify and Rights and Fundamental Freedoms, personal ones have priority in relation to other political,economic, cultural rights, maintaining the classification of known and international acts. They have inseparable, indispensable and inviolable character because they are the cornerstone of the legal order (Article 15). It provides the possibility of the direct and immediate application of law (Article 4). The Constitution also establishes minimum standards of protection of the rights and freedoms set out in the European Convention (Article 17). This characteristic of the constitution should be seen even under the point of view of (Article 122), which provides character prior to the implementation of international agreements in relation to domestic law, when this agreement was ratified by the Parliament of the Republic of Albania.

It should be made a distinction between our Constitution and the European Convention on Human Rights, and we will note a difference between them in relation to the definition of several concepts that are related to trafficking.

So, endurance (Article 26) of the Constitution and (Article 4) of the Convention, at first glance they match with each other. Article 26 stated: "No one shall be required to perform forced labor, except in execution of a judicial decision, the performance of military service, a service that stems from a state of war, from a state of a natural disaster that threatens the life or health of the people ". Now we can notice the difference between them, found that the first paragraph (Section 
4) of the Convention, which makes punishable slavery and servitude, is not included at all in the constitutional provision of (Article 26). This shortage is a result of several factors: time constraints reflects the drafting of the Constitution, disturbing ignorance of the reality of human trafficking, the lack of a tradition in the violations of these rights. This limitation of the Constitution is also observed in the Criminal Code, which will be addressed below. Concepts "slavery" and "exile" are not reflected in JC even a "sentence of forced labor services" (which are provided in the Constitution) is not clearly defined in the CC with the exception of (Article 114 / a) relating to the use of violence, prostitution and trafficking provisions. So, it shows a weakness not only in relation to international acts, but also with internal laws themselves. In this context, to achieve an estimate and a much better approach between the Convention, the Constitution and the Criminal Code, it should be an improvement of legal interest in the Constitution and in JC in connection with the above mentioned problem. However it should be noted that our Constitution does not let this situation entirely without protection, given that it uses as its source the Convention. Also in the arrangement of this situation helps us the logical interpretation (Article 26) of Constitution and (Article 4) of the Convention.According to it, the forced labor is a slight violation of the freedoms and human rights in relation to slavery and servitude, and given that our Constitution sets the standard as border protection from forced labor, it appears that consequently any lower standard is protected. (Elezi, 2005)

The analysis of the Criminal Code shows that the history of legal regulations concerning trafficking begins with Law no. 8733 dated 01.24.2001 "On some amendments to the Criminal Code of the Republic of Albania". Before this analysis should clarify a problem being quite evident today as the treatments are being made by the media but also reports from governmental or non-governmental organizations. Sometimes, by ignorance or intentionally, the notion of human trafficking interpreted in a broader sense provided notions in domestic and international legislation, including the criminal activity related to the realization of benefits from the assistance given to one another person to pass the border illegally or the Albanian state to enter illegally in the territory of another country. In international law, this activity is defined as "Smuggling of migrants", and its meaning is given in the Palermo Protocol as: "The procurement of illegal entry of a person into a state where it is neither a citizen nor a permanent resident, with purpose of obtaining a direct or indirect acquisition of a financial or other material benefit ". This concept is also reflected in(section 289) of CC under the title "Providing assistance for border crossing." In fact, the essential distinction between trafficking and smuggling lies in the fact that trafficking violates the fundamental rights of the individual turning in animals or man craving through abuse of his rights by misusing his aspirations for a better life. The Criminal Code's key provisions that affect human trafficking are (Articles 110 / a, 114 / b, 128 / b of CC honor them, provisions used is 114 / b. For the first time these provisions appear by Law no. 8733 dated. 24.01.2001 "On some of the changes in JC-R.SH ." These changes have come about as a result of the Palermo Protocol ratification. The Criminal Code (Article 110 / a) stipulates as follows according to it:

"The trafficking of men, to material profit or any other profit is punished by imprisonment from five to fifteen years. The same act, if committed in collaboration or more than once or associated with maltreatment and coercion with physical or mental violence to the injured party to perform different actions or consequences of serious health ditch, is punishable by imprisonment for not less than fifteen years and, when there is caused death, life imprisonment.

(Article $114 / \mathrm{b}$ ): "Trafficking of women for prostitution, for the purpose of material profit or any other benefit, punishable by imprisonment from seven to fifteen years. The same act, if committed in collaboration or more than once or associated with maltreatment and coercion with physical or psychological violence to the victim to perform various actions, or causes serious consequences for its health, is punished with imprisonment not less than fifteen years, and when there is caused death, life imprisonment.

(Article $128 / \mathrm{b}$ ): "Trafficking of children for material profit or any other profit, is punished with imprisonment from ten to twenty years. The same act, if committed in collaboration or more than once, or associated with maltreatment and coercion with physical or mental violence, the injured party to perform different actions, or causes serious consequences for health, punishable by imprisonment for not less than fifteen years, and when there is caused death, life imprisonment. These provisions are contained in Chapter II, "offenses against the person", respectively, in section VII, "offenses against liberty". The section VIII, "offenses against freedom and dignity". In Section IX, "offenses against children, marriage and family."

In fact, the definition of trafficking in three provisions and in three different sections represents a misunderstanding regarding the substance of this work, which is a serious violation of the fundamental freedoms of the individual. Trafficking in its essence is not a phenomenon exclusively related to prostitution (although is the most obvious) as it is not associated exclusively with the minor. In this context it would be probably better to predict trafficking of only one section, in section VII, "offenses against liberty," predicting clause separately for special cases, the Indicator.

The three provisions have in common and differences between them, but their meaning is the same.

(Article $114 /$ b) and (128/ b) are forms of trafficking Indicator Seeing these as provided in (Section $110 /$ A) CC 
(Article $114 /$ b) Indicator appears in the circumstances because there are two elements that must be present simultaneously: a) Sex of victim (female), b) Type of exploitation in the purpose of trafficking (exploitation of prostitution). Application of two elements simultaneously previously done at the time when no changes were made to the law no. 9188, dated 12.02.2004. While (Article 128 / b) qualifies the age of the victim only, that is under 18 years old.

1. So, whenever you identify elements of the offense of trafficking and the aggrieved party is not woman and not infant, works would qualify under (Article 110 / a) CC This is the case when the major people, men trafficked for the purposes of forced works.

2. Whenever you identify elements of the offense of trafficking and the injured party is female, is increased, but the purpose of trafficking is not Exploitation of prostitution, works I would qualify under (Article 110 / a) K.P. This is the case when adult females are trafficked for the purposes of family services, forced marriages etc. Regarding the concept of "exploitation of prostitution", it is provided in (Section 114) of the Criminal Code as: "drive, mediation or receiving reward for prostitution, is punishable by fine or imprisonment up to five years." This article viewed carefully approaches favoring more prostitution than its exploitation. Exploitation activities require two elements; realization of benefits and individual abuse.

3. Whenever you identify the elements of the offense of trafficking and the injured party is infant (Although may be female and be used for prostitution), the qualification will be made under (Article $128 / \mathrm{b}$ ).

4. Regarding forecast (Article 114 / b), with the changes that were made in the law No. 9188, dated 12.02.2004. is enough already just one of them, sex of the victim, removing qualifying the scope for exploitation of prostitution. This means that regardless of the purpose for which a woman is trafficked, the qualification will be made under (Article 114 / b) CC So in today's situation,the provisions will apply (Article 110 / a) CC whenever trafficking victims are adult males, regardless of the type of exploitation in the scope of the work will be applied (article114 / b) whenever trafficking victims are adult women, regardless of the type of exploit and will be applied (Article $128 / \mathrm{b}$ ) whenever trafficking victims are minors, regardless of the type of target exploitation.

\section{Prevention of Trafficking}

Albanian state and society, compared with the past decade have increased efforts to crack this form of crime being recognized as one of the most serious forms of violations of human rights and fundamental freedoms. Set of measures and programs for the prevention of criminogenic factors, taken as a going concern during the years 2001-2006, have led to positive results. So, Albania is not reported since 2003 , as a transit country for victims of trafficking launched by other countries of origin. The census figures of proceedings, concluded that in 2005 this number was reduced by about $65-70 \%$ in comparison with 2002. This has come as a result of taking various measures such as: Legislative measures, Since December 2000, the Albanian state has signed the Palermo Convention and its two Additional Protocols relating to trafficking which is ratified by law nr.9820 dt.11.07.2002. In this way, our country joined international efforts to coordinate efforts to combat this phenomenon. Another action in the context of legislative measures is and ratification by Parliament in the "Convention on Action against Trafficking in human beings". 2001 Law No. 8733 "On some amendments to the Criminal Code of RA" was the most important measures of the criminal character of the efforts to prevent this phenomenon. Of particular importance is and dt.30.09.2004 9284 law "On the prevention and combat of organized crime", which aims to prevent and fight organized crime through detection, identification, seizure and confiscation of illegal persons suspected of participating in organized crime and trafficking. Also nr.9205 dt.15.03.2004 law. "For the protection of witnesses and collaborators of justice" is an important legislative measure regarding the fight against organized crime and trafficking. This law aims to provide key evidence for claims and criminal processes related to organized crime, which hampered to ensure, by threats and the lack of guarantees that the State is to ensure citizens. Organizational measures, among the most important measures was the establishment of organizational structures specialized in attacking organized crime, including trafficking. Raising the Court for Serious Crimes, High Crimes Prosecution Offices and against trafficking through the Police Departments across regions, with subject matter jurisdiction and prosecution of trafficking in human beings, constitutes a very important measure in this regard. Particular importance, have been among organizational measures and the adoption of the National Strategy against Trafficking in human beings in 2001, which includes in particular a strategy against child trafficking. This strategy shows the beginning of a job organized by the Albanian state and society in the fight against this phenomenon, concentrating the work on all three aspects of prevention: - primary prevention, which includes measures to address the whole population to prevent the possibility of performing that crime - secondary prevention, which includes measures to prevent persons involvement in these crimes, - comprising tertiary prevention measures for minimizing of authors and their re-introduction in this activity. 
As part of the most important structures in the prevention and fight against trafficking based on nr.203 Prime Minister's Order dated 19.12.2005, near the National Coordinator for Anti-Trafficking / deputy interior, Anti-Trafficking Unit was established, whose main tasks are: Monitoring the activities of institutions engaged in implementing the National Strategy for Combating Trafficking in human beings, coordination of work with these institutions, collection of information and data on issues related to this phenomenon etc.

Educational measures, These measures aimed to orient in two directions: first, we measure the population and educational potential victims of trafficking and secondly, we measure educational law enforcement structures. In the context of prevention of trafficking, MES has issued Instruction No. 6, dated 29.03.200. "On registration of Roma pupils in schools that are not equipped with a birth certificate. Rehabilitation measures, under these measures, is developed a standardized questionnaire to help the police structures that make first contact with the victims. Currently, in all border points where is the return of deportees, border police interview them in order to identify and protect potential victims of trafficking. National Reception Center for Victims of Trafficking (NRC) do a job for awareness of trafficking victims, that they denounce their traffickers. Besides this center, there are series of other non-governmental organizations with more impact in this regard, as the Center "Vatra" in Vlora, "Next Vision", "Different and Equal", "International Social Service", "Terre des Hommes" "Help for Children", "Community Center" in Ballesh, "International Catholic Migration Commission", "Save the Children" etc.

\section{References}

Constitution of Albania., Top I- provides "General Principles", Chapter II, "Personal Rights and Freedoms", Chapter III "Liberties and Political Rights, Chapter IV" Economic Liberties and Rights, Social, and Cultural Rights, Chapter V " Social Objectives ", Chapter VI" Ombudsman ".

Criminal Code's key provisions that affect human trafficking: (Articles 110 / a, 114 / b, 128 /b

Elezi, I. (2005). "Commentary to Criminal Law, Special Part". Tirana. pp 132-136.

European Convention on Human Rights, Articles 15,4,17

Handbook for Parliamentarians (2005). "Fight Against Child Trafficking". (Vol.9). Tirana. pp 16-26.

Hysi, V.(2005). Criminology. Tirana. pp. 173-174

Law no. 8733 dated 01.24.2001 "On some amendments to the Criminal Code of the Republic of Albania"

Law no. 9284 dated 30.09.2004 «On the prevention and combat of organized crime", Law nr.9205 dated 15.03.2004 "For the protection of witnesses and collaborators of justice"

Leskaj, V., Dragoti, E., Karaj, Th.,Todhri, F., Albanian Society of Traffic Challenges Facing Women and Girls. Tirana.pp 18-19.

Meçani, D. (2006). "Offence of Trafficking in Women, Opinions and Comments". Tirana: Publishing House "MALUKA". pp 15-16.

Prime Minister's Order no.203 dated 19.12.2005, the establishment of Anti-Trafficking Unit near the National Coordinator for AntiTrafficking / deputy interior

Psycho-Social Centre "Vatra ". Girls and Trafficking.(2003). Tirana. pp 5-6, 13-14. 
